(cosmic radiation centre), Centre National d'Etudes de Telecommunications, Institut d'Astrophysiques (Paris) and the Institut de Géophysique (Paris).

The programme of experiments calls for the launching of 37 high-altitude balloons, (27 French and 10 Russian) carrying loads of recording equipment of from $100 \mathrm{~kg}$ to 10 tonnes, over a period of 2 months. The polythene balloons themselves each weigh $250 \mathrm{~kg}$.

The two stations lie at the ends of the same line of magnetic force, and by making simultaneous observations from both, it is hoped to investigate the variations of the radiation pattern in near space and the course of the entry of charged particles into the atmosphere. In particular, data are expected on the effect of the solar wind, and consequent magnetic storms, on the ionization of the upper atmosphere and the disruption of telegraphic and radio-telephone communications. It is hoped that these experiments will lead to practical improvements in spacecraft safety, and greater reliability of radio communications and navigation.

\section{SOCIAL MEDICINE Abortion Act in Action}

THE Abortion Act is working better than either its opponents or its adrocates hoped, according to a preliminary survey by P. Diggory, J. Peel and M. Potts (Lancet, i, 287; 1970). From the data for the first year and a half of its operation and estimates of the pattern of abortion over the past ten years, they conclude that the total of 65,000 legal abortions in England and Wales represents the continuation of a trend that has existed for at least a decade and that there has been no net increase in the number of abortions. There has instead been a switch from criminal abortions to therapeutic abortions under the National Health Service.

The act seems to have worked particularly well in ensuring minimum delays between seeking abortion and its performance; some 85 per cent of all terminations were carried out before the thirteenth week of pregnancy. Dr Peel believes that the proposed amendments to the act, which insist on the supervision by a doctor of consultant status, would inevitably increase the delays.

The abortion rate in Britain has been rising steadily from 6,000 in the first quarter since the act was implemented in April 1968 to 16,000 in the last quarter of 1969 , but the rate of increase now seems to be levelling off. An encouraging sign is that the proportion of terminations carried out under the National Health Service has increased from 60 per cent of the total in the first quarter to 65 per cent in the final quarter. The regional discrepancies in the availability of National Health abortions also seem to be narrowing. In Sheffield, for instance, the abortion rate in the first half of the second year was 80 per cent greater than in the first year. In Liverpool the increase was 70 per cent, and even in Birmingham, where many doctors are opposed to abortion, there was an increase of 50 per cent. By far the greater proportion of all the private abortions, however, are in the north-west London area.

The chief contention, that there has been no net increase in abortions, is difficult to support statistically because there are no reliable figures for the number of criminal abortions performed before the act was passed. 'To support their argument, the authors show that the estimated increase of 6,000 in the total number of National Health Service and private abortions during 1967 was accompanied by a decrease of 2,000 in the total number of admissions for spontaneous and criminal abortions. On the assumption that only a quarter to a fifth of criminal abortions are admitted to hospital, it seems likely that most of what would have been criminal abortions were transferred to the private sector. Evidence for the rising trend in abortions in the years before the act comes from the increase in the number of National Health Service terminations from 2,000 in 1961 to 10,000 in 1967 and from Dr Diggory's estimates that the number of private therapeutic abortions has risen from 12,000 to 18,000 during the same period.

The act has been remarkably successful in reducing the death rate from abortion. The latest figures from the Ministry of Health show that in England and Wales the number of deaths from abortion, which has been between 45 and 50 per year for the past twenty or so years, dropped to 22 during 1969 . It is estimated that, of these, three were due to private legal abortions, ten to National Health abortions and the remaining nine to criminal abortions.

Although the number of deaths from abortion is quite low, there is an urgent need for more research into the best techniques for abortion and into possible long term complications of the operation. But the chief point to emerge from the report is the need to improve contraceptive services. The survey has shown that "many women who have knowledge of and access to contraception fail to use it and yet are dismayed by the resultant pregnancy. . . . Diggory's series of 1,000 abortions included 18 women doctors, 99 nurses, 84 students and 29 teachers". Furthermore, the provisions of the 1967 Family Planning Act for contraceptive advice to be given to the unmarried have been fully implemented by only 39 out of 250 local authorities.

\section{CONSERVATION}

\section{Environmental Postgraduates}

HerTot-WATT University has made a positive response to the growing interest in the environment. It has set up a one year postgraduate course leading to an MSc degree in environmental conservation. The course, which will be under the control of the joint department of architecture of Heriot-Watt and Edinburgh School of Art, aims to provide a study of the techniques involved in physical preservation, together with an interdisciplinary approach to the planned integration of existing buildings, sites and town areas, with new developments. Mr Peter Whitson, the director of the course, said that it will concentrate on "the conservation of areas, keeping what is good in the traditional, but relating it to the modern demands of traffic management, local government, law, finance and sociological implications".

Subjects studied will include the theory and practice of environmental conservation, together with its history and planning, and students will also look at the technology of conservation. The course will start next October, and it will take students with good honours degrees, preferably in architecture, town planning, landscape, building and social studies. 